\title{
Gas dispersion modelling in a critical infrastructure area
}

\author{
Petr Michálek ${ }^{1, *}$, David Zacho ${ }^{1}$ and Nikola Žižkovský ${ }^{1}$ \\ ${ }^{1}$ VZLU - Czech Aerospace Research Centre, Department of Aerodynamics, Beranových 130, 199 05Praha 9, Czech Republic
}

\begin{abstract}
Experimental investigation of gas dispersion in a critical infrastructure area was performed using a boundary layer wind tunnel. The dispersion of gases is evaluated from the point of view on required function of security systems in case of critical infrastructure accident involving airplane attack. Physical model of the critical infrastructure installed in the wind tunnel is subjected to measurement of gas concentration with flame ionisation detectors.
\end{abstract}

\section{Introduction}

Critical infrastructures, such as power plants, are fundamental part of state infrastructure and must provide power for the other necessary parts to function properly. The power plants might be vulnerable to terrorist attacks or accidents using large aircrafts, i. e. Boeing 737 or Airbus A330, which contains thousands litres of jet fuel. The impact of the aircraft and subsequent fire of the fuel might damage the critical infrastructure and thus cause its malfunction. This paper describes modelling of gas dispersion in an area of the critical infrastructure facility in case of a large aircraft impact.

The fire and smoke dispersion of burning jet fuel in the vicinity of critical infrastructure buildings will be evaluated in a computational model. The fire and smoke dispersion will be evaluated from the point of view on required function of security systems in case of critical infrastructure accident involving intentional airplane attack. The physical modelling of the dispersion inside critical infrastructure area will serve for validation and comparison with the computational model.

Recent and not so recent work in VZLU in the area of gas dispersion included dispersion around train station [1] and dispersion in large urban area [2] and detailed model from the same area [3]. Dispersion over an coal mine [4] and effects of wind fences porosity were studied in Czech Republic as well [5]. The safety of nuclear power plants against aircraft attack was studied e.g. in [6].

\section{Gas dispersion modeling}

\subsection{The boundary layer wind tunnel}

The experimental work was done in the boundary layer wind tunnel (BLWT) in VZLU, a. s. The BLWT is an open-circuit wind tunnel with cross section $1.8 \mathrm{~m}$ wide and $1.5 \mathrm{~m}$ high with adjustable ceiling. The test section for boundary layer development is $13.6 \mathrm{~m}$ long. The tunnel is powered by $55 \mathrm{~kW}$ fan. Maximal velocity above the boundary layer is ca. $25 \mathrm{~m} \cdot \mathrm{s}^{-1}$. Reference velocity above the boundary layer is measured with Pitot-static probe and hot-wire probe. The model space is equipped with $1.75 \mathrm{~m}$ dia. turntable and traversing device for moving the probe in all three directions $\mathrm{x}, \mathrm{y}$, z. The simulation means can create agricultural, suburban or urban boundary layer according to Eurocode 1 [7]. The boundary layer developed over the entire test section with plastic sheet with $7 \mathrm{~mm}$ high truncated cones and a rectangular barrier $140 \mathrm{~mm}$ high, which served as turbulence generator. This boundary layer corresponds with terrain type III (suburban).

\subsection{The critical infrastructure model}

The physical model of the critical infrastructure was manufactured in scale 1:660 on the basis of supplied CAD model. The model includes buildings larger than $10 \mathrm{~m}$ in full scale and connecting above-ground pipelines. Railway tracks and power lines were not modelled. Buildings were cut out of synthetic wood and cooling towers were $3 \mathrm{D}$ printed. The terrain inside the studied area is nearly flat. The model is depicted in Figure 1; main flow direction is from right to the left.

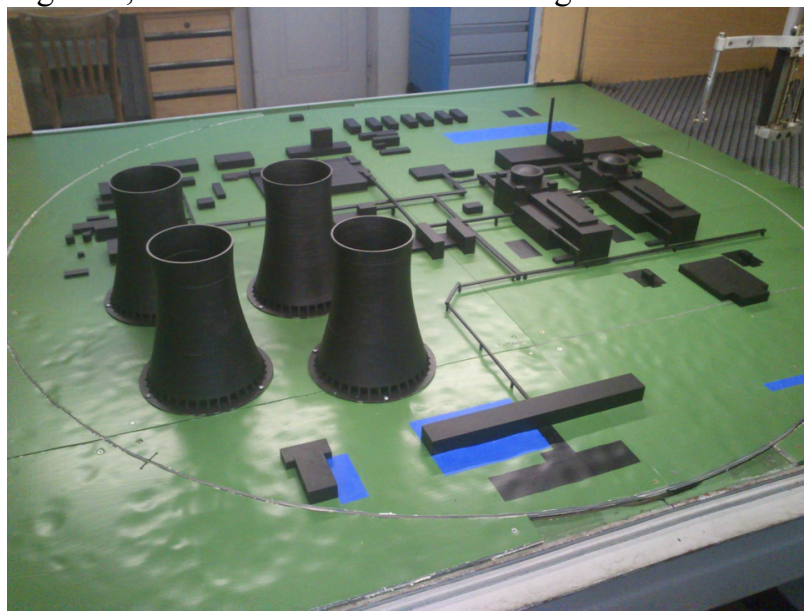

Fig. 1. The physical model of the critical infrastructure

\footnotetext{
Corresponding author: michalek@,vzlu.cz
} 
The attack scenario describes worst possible impact area between the two main block buildings, so the emission source was installed there near the second main block building. The emission source is a small chamber sized $25 \times 25 \times 10 \mathrm{~mm}$ covered with filtration fabric. The source is visible as white square in Figure 1 between the main block buildings at left side. The main block buildings are especially vulnerable through the ventilation openings on their facades, so the concentration measurements were focused on the positions of the openings. The model was installed on a turntable, so measurements of different wind directions were made possible. Scheme of ventilation openings are presented in Figure 2, where the openings are marked on the buildings with numbers. The southwest facade (not depicted) also contains one ventilation opening No. 23. The scheme of entire critical infrastructure area is shown in Figure 3, where north direction is at the top of the picture. The impact point and the source of emission in marked with red dot.
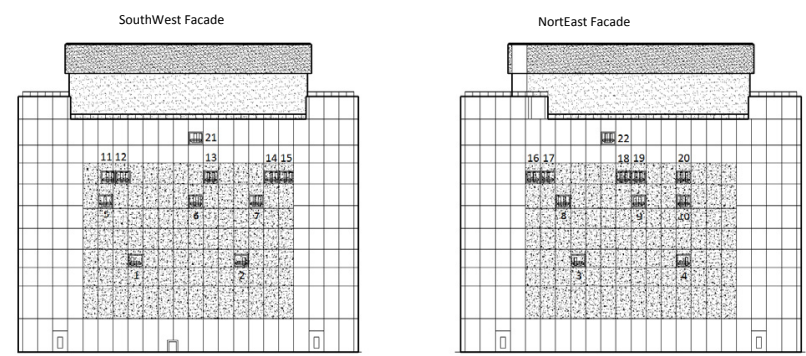

Fig. 2. Ventilation openings on the main block building

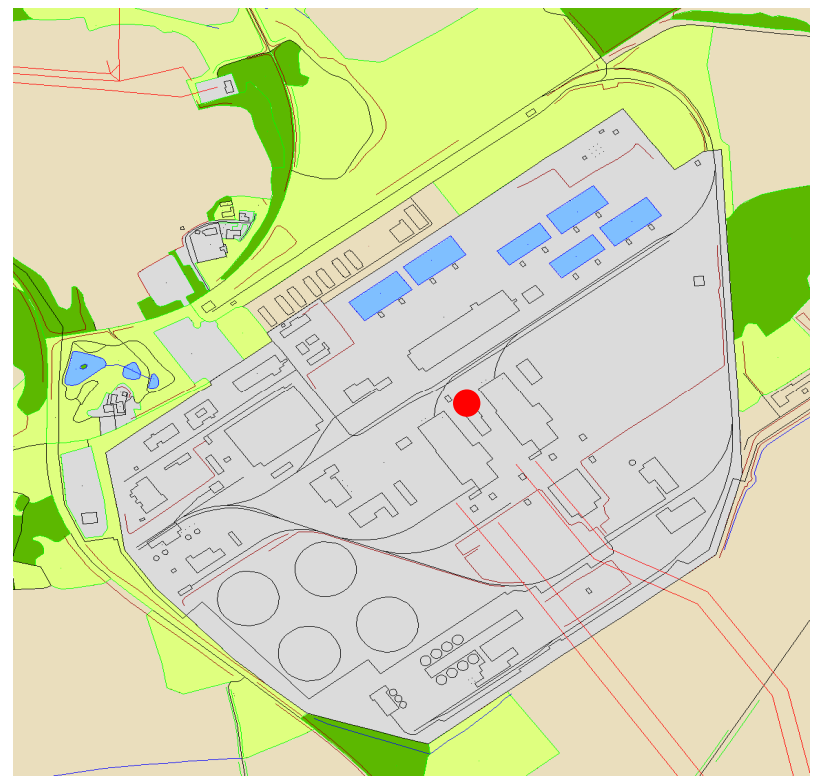

Fig. 3. Scheme of the entire area

\subsection{Flow and dispersion measurements}

The flow field of the incoming boundary layer was measured with single-sensor hot-wire probe and the concentration at desired points was measured with flame ionization detector (FID). The vertical mean velocity profile is shown in Figure 4, where $\mathrm{U} 4\left(\mathrm{~m} \cdot \mathrm{s}^{-1}\right)$ is longitudinal component of velocity vector, $\mathrm{I}_{\mathrm{u} 4}(\%)$ is turbulence intensity of the component $\mathrm{U}$ and $\mathrm{z}(\mathrm{mm})$ is vertical height above the ground. The velocity profile corresponds with its typical logarithmic shape.

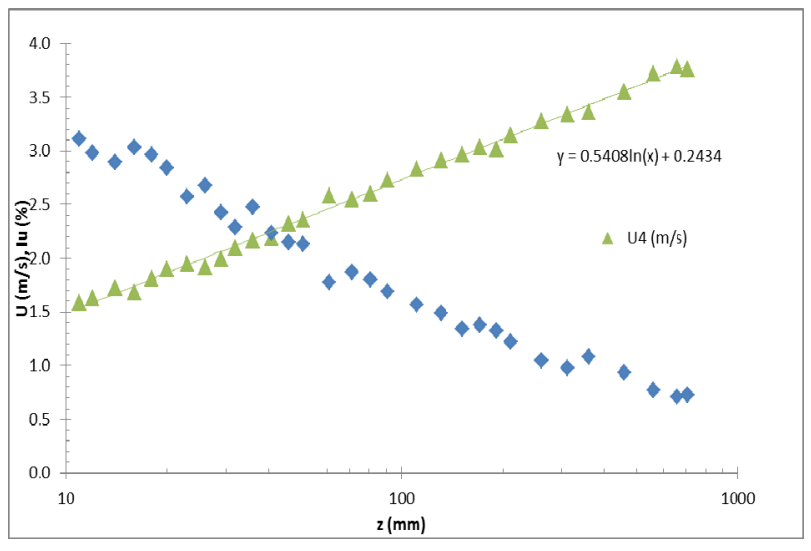

Fig. 4. The boundary layer velocity profile

The wind tunnel velocity was set to ca. $4.4 \mathrm{~m} \cdot \mathrm{s}^{-1}$ above the boundary layer and this reference velocity was used in the dispersion experiments as well. For this size of the modeled area, the small-scale similarity criteria applies, which means that the minimal Reynolds roughness number $\mathrm{Re}^{*}$ has to be satisfied. This ensures invariance of the flow pattern around the structure on the main flow velocity. The Reynolds roughness number is defined as

$$
\mathrm{Re}^{*}=\mathrm{z}_{0} \times \mathrm{u}^{*} / \mathrm{v}=8.7 \geq 1
$$

where $v$ is kinematic viscosity of air $\left(\mathrm{m}^{2} \cdot \mathrm{s}^{-1}\right), \mathrm{u}^{*}$ is frictional velocity $\left(\mathrm{m} \cdot \mathrm{s}^{-1}\right)$ and $\mathrm{z}_{0}$ is aerodynamic roughness $(\mathrm{m})$. Values of $\mathrm{u}^{*}=0.22 \mathrm{~m} \cdot \mathrm{s}^{-1}$ and $\mathrm{z}_{0}=$ $0.64 \mathrm{~mm}$ were derived from the logarithmic fit of the mean velocity profile.

A mixture of tracer gas (ethane) and compressed air was released from the source using flow controllers. The volume flow of ethane was $0.31 \cdot \mathrm{min}^{-1}$ and air flow was $5.11 \cdot \mathrm{min}^{-1}$. Concentration field was measured using suction tube mounted on a traversing device. The suction tube was connected via stainless steel tubing to a peristaltic pump and a flame ionization detector (FID). FIDs use ionized hydrogen flame to burn the incoming sample and then measure the electric current through the flame. The FID signal is measured with the electrometer and then sampled and saved in computer. Sampling frequency was $100 \mathrm{~Hz}$ and sampling time was 1 min for each measuring point and then $30 \mathrm{~s}$ waiting to move to the next point so that the previous sample clears the tubing. FID calibration was made with calibration gas mixture with precise concentration $1000 \mathrm{ppm}$ (parts per million) of ethane in air.

\section{Results}

The concentration measurements were made at the ventilation points for all of the main wind directions and selected other wind directions. 
The FID signals were converted into concentration with LabView software and then mean values were calculated for each point. The response of the measuring chain does not allow fluctuation measurements. Figure 5 presents concentration near ventilation openings at SE wall of block 1, where Sv1 etc. corresponds with numbers of ventilation openings in Figure 2. Wind direction at $0^{\circ}$ corresponds to SE wind. Maximal concentration values appear at wind direction $180^{\circ}$, when the SE wall of block 1 lies in the wake of block 2 and thus accumulation of emissions from the source can occur in the wake. Other values near zero can be considered as zero.

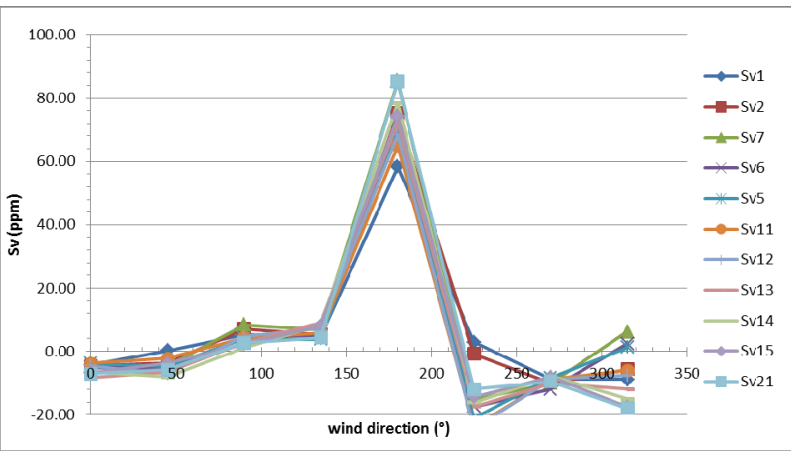

Fig. 5. Concentration near ventilation openings, SE wall of block 1

Figure 6 presents concentration at ventilation openings at NW wall of block 1, except of opening Sv23, which lies at $\mathrm{SW}$ wall. High concentration was measured at wind direction $0^{\circ}$, which equals to SE wind here. In this wind direction the NW wall lies in the wake of block 1, which supports accumulation of the emission. Lower values were measured also at 180 degrees (NW wind), where NW wall lies in the wake of block 2 .

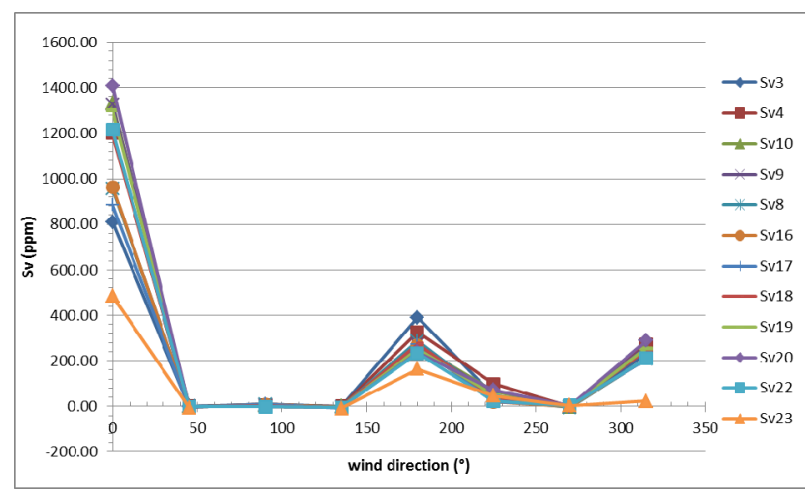

Fig. 6. Concentration near ventilation openings, NW wall of block 1

Figure 7 presents concentration at ventilation openings at SE wall of block 2. These concentration exhibit high values again at wind direction $180^{\circ}(\mathrm{NW})$ and $225^{\circ}(\mathrm{N})$, where SE wall lies in the wake of block 2 . The values reach the highest level, because this wall is the nearest from the source.

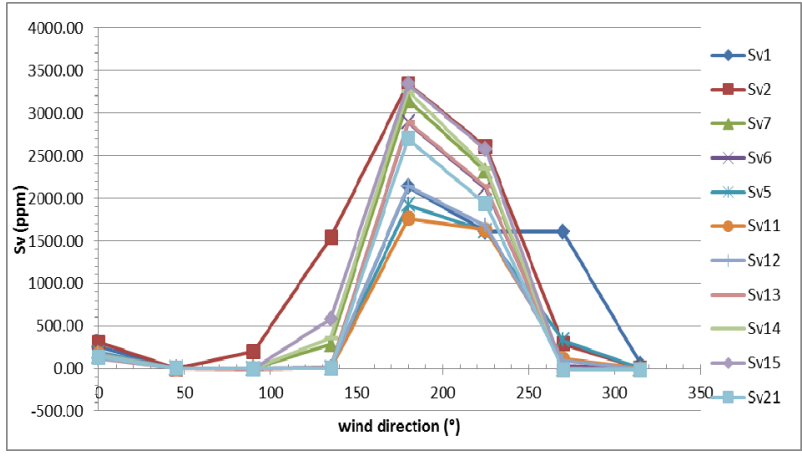

Fig. 7. Concentration near ventilation openings, SE wall of block 2

Figure 8 presents concentration at ventilation openings at NW wall of block 2 . The values rise at wind direction $45^{\circ}(\mathrm{S})$, where the NW wall lies in the wake of block 2 . Line representing opening Sv23 reaches its highest value at $225^{\circ}(\mathrm{NE})$, where the opening No. 23 lies in the wake of block 2 and at $0^{\circ}(\mathrm{SE})$, where it lies near the wake of block 1 .

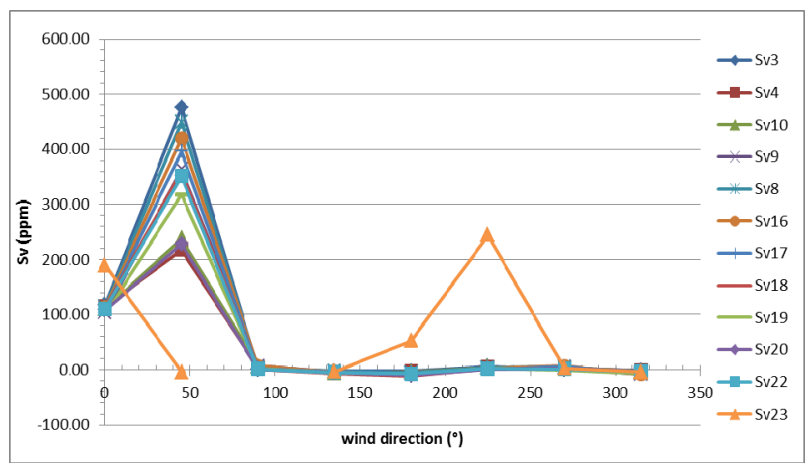

Fig. 8. Concentration near ventilation openings, NW wall of block 2

\section{Conclusions}

Gas dispersion was studied on a physical model of critical infrastructure area. Concentration was measured at the ventilation openings of the main block buildings. Highest values were found in the case where the walls with openings lie in the wake of the main block building. The experimental data will be used for verification and validation of the computational model. The results and routines of the computational model could be used for other critical infrastructure objects in the future, for increase of reliability and safety of buildings and technology.

\section{Acknowledgements}

Authors thank for the support from the Ministry of Interior of Czech Republic under project VI20172020092 - Simulation of fire and smoke dispersion in critical infrastructure area in case of accident or aircraft attack. 


\section{References}

1. R. Ulman, Z. Janour, H. Sedenkova, J. Drbohlav, Proceedings of EACWE4, Prague (2005), paper \#189

2. P. Michálek, D. Zacho, Engineering Mechanics 2015, p. 85 (2015)

3. P. Michálek, D. Zacho, EPJ Web of Conferences 143, 02074 (2017)

4. S. Nosek, Z. Janour, L. Kukacka, K. Jurcakova, R. Kellnerova, E. Gulikova, EPJ Web of Conferences 67, 02084 (2014)

5. S. Nosek, R. Kellnerova, K. Jurcakova, Z. Janour, H. Chaloupecka, M. Jakubcova, EPJ Web of Conferences 114, 02084 (2016)

6. J. Králik, Applied Mechanics and Materials Vol. 617 (2014), pp 76-80

7. Eurocode 1: Actions on structures - Part 1-4: General actions - Wind loads (EN 1991-1-4), European Committee for Standardization, Brussels (2005) 